\title{
Chronic lymphocytic leukemia B cells contain anomalous Lyn tyrosine kinase, a putative contribution to defective apoptosis
}

\author{
Antonella Contri, ${ }^{1,2}$ Anna Maria Brunati, ${ }^{3}$ Livio Trentin, ${ }^{1,2}$ Anna Cabrelle, ${ }^{1,2}$ \\ Marta Miorin, ${ }^{1}$ Luca Cesaro, ${ }^{3}$ Lorenzo A. Pinna, ${ }^{2,3}$ Renato Zambello, ${ }^{1,2}$ \\ Gianpietro Semenzato, ${ }^{1,2}$ and Arianna Donella-Deana ${ }^{3}$
}

\begin{abstract}
1Department of Clinical and Experimental Medicine, Clinical Immunology Branch, Padua University School of Medicine, Padua, Italy. ${ }^{2}$ Venetian Institute for Molecular Medicine (VIMM), Centro di Eccellenza per la Ricerca Biomedica, and ${ }^{3}$ Department of Biological Chemistry, University of Padua, Padua, Italy.
\end{abstract}

\begin{abstract}
B cell chronic lymphocytic leukemia (B-CLL) is a neoplastic disorder characterized by accumulation of B lymphocytes due to uncontrolled growth and resistance to apoptosis. Analysis of B cells freshly isolated from 40 patients with chronic lymphocytic leukemia demonstrated that the Src kinase Lyn, the switch molecule that couples the B cell receptor to downstream signaling, displays anomalous properties. Lyn is remarkably overexpressed at the protein level in leukemic cells as compared with normal B lymphocytes, with a substantial aliquot of the kinase anomalously present in the cytosol. Whereas in normal B lymphocytes Lyn activation is dependent on B cell-receptor stimulation, in resting malignant cells, the constitutive activity of the kinase accounts for high basal protein tyrosine phosphorylation and low responsiveness to IgM ligation. Addition of the Lyn inhibitors PP2 and SU6656 to leukemic cell cultures restores cell apoptosis, and treatment of malignant cells with drugs that induce cell apoptosis decreases both activity and amount of the tyrosine kinase. These findings suggest a direct correlation between high basal Lyn activity and defects in the induction of apoptosis in leukemic cells. They also support a critical role for Lyn in B-CLL pathogenesis and identify this tyrosine kinase as a potential therapeutic target.
\end{abstract}

\section{Introduction}

B cell chronic lymphocytic leukemia (B-CLL) is the most common leukemia in adults and is characterized by the accumulation of mature B lymphocytes in the $G_{0} / G_{1}$ phase of the cell cycle, expressing B cell-related (i.e., CD19, surface Igs) and -unrelated (CD5 and CD23) molecules $(1,2)$. At an early stage of the disease, B lymphocyte accumulation is likely to be consequent to an undefined defect in the apoptotic machinery rather than to an increase in proliferation of leukemic cells $(3,4)$. Several approaches have been developed to identify selective targets for new therapeutic strategies in this disorder. Particular attention has been devoted to the clinical utility of molecules recognizing surface membrane antigens (i.e., CD20 and CD52) $(5-8)$. By contrast, the signal transduction pathways underlying the abnormalities of these leukemic cells are poorly understood. No data are available on deregulated cell signaling in B-CLL. In this regard, it is known that malignant CLL B cells express low levels of surface Igs, as well as Ig $\alpha$ and $\operatorname{Ig} \beta$ (CD79a and CD79b), which compose the $\mathrm{B}$ cell receptor (BCR) $(3,4,9-13)$. This pattern is associated with the functional deficiency of leukemic cells to capture and respond to antigens. This BCR deficiency has been associated with several abnormalities of the heterodimer, especially the CD79b. This finding has been thought to be consequent to reduced expression of CD79b mRNA, mutations, and

Nonstandard abbreviations used: B-CLL, B cell chronic lymphocytic leukemia; BCR, B cell receptor; CLL, chronic lymphocytic leukemia; CsA, cyclosporin A; Dex, dexamethazone; EGCG, epigallocatechin-3-gallate; ITAM, immunoreceptor tyrosinebased activation motif; PI, propidium iodide.

Conflict of interest: The authors have declared that no conflict of interest exists.

Citation for this article: J. Clin. Invest. 115:369-378 (2005)

doi:10.1172/JCI200522094 overexpression of a product derived from an alternative splicing of CD79b $(9-12,14,15)$. Although a dysregulation of BCR has been reported in this disease, little is known about the cell signaling delivered by BCR ligation in leukemic cells obtained from B-CLL patients (16). A better understanding of the molecular etiology of B-CLL, that is, the identification and functional characterization of the signaling protein(s) that are responsible for this disease, will undoubtedly provide important clues to the clinical behavior of B-CLL and might suggest new potential targets for effective therapy.

Normal B cells are instructed continuously by BCR signals to make crucial cell-fate decisions at several checkpoints during their development. Recent evidence has clarified how BCR signals regulate cell fate (17-19). Current concepts support a model in which BCR engagement leads to the phosphorylation of the immunoreceptor tyrosine-based activation motifs (ITAMs) located in the cytoplasmic tails of CD79a/CD79b by the Src-related tyrosine kinase Lyn. ITAM phosphorylation creates the docking sites for the recruitment and activation of the Syk tyrosine kinase $(18,20)$. This triggers downstream signals leading to cellular proliferation, survival, or apoptosis, depending on cosignals received by the cell and the stage of cellular differentiation (17).

Because Lyn activation plays a pivotal role in the signaling cascade triggered by BCR engagement, we investigated whether this kinase may be involved in the pathogenesis of chronic lymphocytic leukemia (CLL). In the present study, we demonstrate that in B-CLL, as compared with normal B cells, the Lyn protein is upregulated and shows a different subcellular localization. Moreover, tyrosine kinase displays a remarkable constitutive activity, which leads to an increased basal tyrosine protein phosphorylation and a low responsiveness to BCR ligation. 


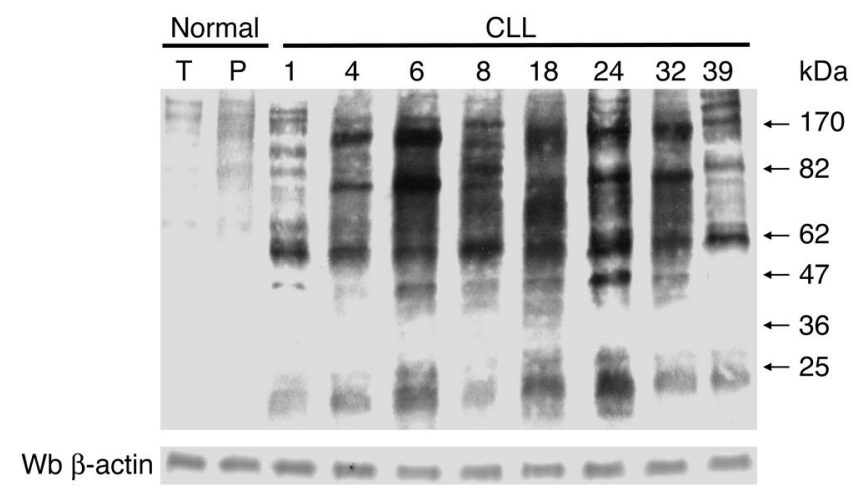

Figure 1

Analysis of protein tyrosine phosphorylation in normal and CLL B cells. Immunoblot analysis of cellular tyrosine-phosphorylated proteins in normal B cells, from both tonsil $(T)$ and peripheral blood $(P)$, and in leukemic B-CLL cells. Cells were lysed, and the proteins were analyzed by Western blotting $(\mathrm{Wb})$ and immunostaining with antibody against phosphorylated tyrosine. The filter was reprobed with anti- $\beta$-actin antibody as loading control. The molecular mass of protein standards is indicated on the right. The data are representative of experiments performed with 3 different tonsils, 5 peripheral blood samples, and 40 B-CLL samples.

While amount and activity of Lyn are decreased by drugs that induce apoptosis in cultured CLL B cells, Lyn inhibitors remarkably reduce the survival of the leukemic cells.

\section{Results}

Protein tyrosine phosphorylation is abnormal in B-CLL. The cellular protein tyrosine phosphorylation of $B$ cells is reported in Figure 1. Normal B lymphocytes, used as controls, showed a very low tyrosine phosphorylation, whereas freshly isolated leukemic cells from the 40 patients analyzed displayed abnormally high immunostaining for phosphorylated tyrosine. CLL samples shown in Figure 1 were selected in order to include patients defined by different clinical stages (Table 1 ) and representative of the different protein tyrosine phosphorylation patterns obtained. In particular, the Western blots shown for samples 6, 24, and 39 were the most representative in our series of patients.

To gain information about the tyrosine kinase(s) responsible for the high basal B-CLL tyrosine phosphorylation, we cultured the leukemic cells obtained from CLL patients in the presence of the following inhibitors selective for different tyrosine kinases: PP2 and SU6656 (Src family) (21); piceatannol (Syk) (22); LFM-A13 (Btk) (23); tyrphostin AG490 (JAK2, JAK3) (24); tyrphostin AG1296 (platelet-derived growth factor $\alpha$ - and $\beta$-receptor kinases, c-kit) (25); and tyrphostin AG1478 (epidermal growth factor receptor kinase) (26). Figure $2 \mathrm{~A}$ shows representative experiments obtained with 2 CLL samples. Only the addition of PP2 and SU6656 almost abolished cellular immunostaining for phosphorylated tyrosine, demonstrating that the abnormal B-CLL tyrosine phosphorylation was catalyzed by tyrosine kinase(s) sensitive to these inhibitors. PP2 and SU6656 are the most potent and selective inhibitors for tyrosine kinases of the Src family. As their structures are unrelated, few nonspecific effects of PP2 differed from those of SU6656. Accordingly, the combined use of these two inhibitors has been suggested for identifying the specific physiological roles of Src kinases (21).
Genistein, a nonselective inhibitor of BCR-induced tyrosine phosphorylation (27), partially reduced the cellular tyrosine phosphorylation only at high concentrations, which also affected Src kinases (28) (Figure 2A).

To support the specificity of the Src-kinase involvement in B-CLL basal tyrosine phosphorylation, leukemic cells cultured without and with tyrosine kinase inhibitors were lysed and the tyrosine kinase activity of the cellular lysates was tested in vitro on either an Src-specific or a nonspecific substrate. The selective inhibition by PP2 and SU6656 of the kinase activity tested on the Src-specific peptide cdc2(6-20) (29) demonstrated that constitutive Src activity was indeed present in B-CLL lysates and was downmodulated by the highly selective inhibitors under these conditions (Figure 2B). In parallel, the finding that, among the inhibitors used, only PP2 and SU6656 abrogated the kinase activity tested on the nonspecific substrate polyGlu $\mathrm{Tyr}_{\mathrm{r}}$ (Figure 2C) confirmed that the total cellular tyrosine kinase activity was catalyzed by enzyme(s) belonging to the Src family.

Lyn protein level is overexpressed in CLL B cells. Because Lyn is a member of the Src family, which is predominantly expressed in B lymphocytes and is one of the first molecules involved in transducing signals from $\operatorname{BCR}(17,18,30-32)$, we evaluated the amount of Lyn protein present in leukemic B cells recovered from CLL patients with respect to normal B cells. As compared with control B lymphocytes, all 40 B-CLL samples analyzed expressed higher amounts of both p53 and p56 Lyn isoforms (Figure 3A). Densitometric analysis of Lyn protein content showed a B-CLL overexpression ranging between 2.5 - and 5-fold greater than the amount observed in normal B cells. In contrast, Western blot analysis of Src, Fyn, c-Fgr, and Lck demonstrated that the cellular protein amounts of these Src kinases were similar in normal and leukemic cells (Figure 3A).

Lyn distribution analyzed in normal $\mathrm{B}$ cells by confocal microscopy (Figure 3B) appeared punctate and random across the plasma membrane. In contrast, a more intense and coalescent fluorescence revealed that an abnormal amount of Lyn was present in the plasma membrane of leukemic cells (Figure 3B).

To determine whether the abnormally high Lyn protein expression in leukemic B cells resulted from deregulated transcription, we examined the expression of the mRNA encoding the tyrosine kinase. Similar amounts were found in leukemic and normal B lymphocytes as judged by both Northern blot analysis of 16 B-CLL samples (Figure 3C) and RT-PCR analysis of 40 B-CLL samples (data not shown).

Lyn is constitutively active and poorly responsive to BCR engagement in $B$-CLL. Because Lyn is downregulated in unstimulated normal B cells and becomes active after BCR engagement (30-32), we next investigated enzyme activity in freshly isolated and BCR-engaged B lymphocytes. Lyn activity was almost undetectable in controls, including tonsil B cells, total peripheral $B$ lymphocytes, naive peripheral B lymphocytes, and memory peripheral B lymphocytes (Figure 4A). In contrast to normal $\mathrm{B}$ cells, the tyrosine kinase was constitutively active in leukemic cells isolated from CLL patients, as demonstrated by the remarkable kinase activity displayed in vitro by the anti-Lyn immunocomplexes (Figure 4A). These findings did not correlate with the expression of ZAP-70 or with the presence or absence of somatic mutations. The finding that tyrosine kinase activity was undetectable in immunoprecipitates obtained in parallel experiments with anti-Src, anti-Fyn, anti-c-Fgr, and 
Table 1

Biological and clinical characteristics of the patients

\begin{tabular}{|c|c|c|c|c|c|c|c|c|c|c|c|c|c|}
\hline $\begin{array}{l}\text { Patient } \\
\text { no. }\end{array}$ & Age & Sex & $\begin{array}{c}\text { Rai } \\
\text { stage }^{A}\end{array}$ & $\begin{array}{l}\text { wbc count } \\
\left(/ \mathrm{mm}^{3}\right)\end{array}$ & $\begin{array}{c}\text { Lymphocytes } \\
(\%)\end{array}$ & $\begin{array}{c}\mathbf{V}_{\mathrm{H}} \text { mutational } \\
\text { status }^{\mathrm{B}}\end{array}$ & $\begin{array}{c}\text { ZAP-70 } \\
\text { expressionC }\end{array}$ & $\%$ CD19/5 & $\%$ CD38 & $\%$ CD79b & $\%$ slgM & $\begin{array}{l}\text { slgM } \\
\text { (MFI) }\end{array}$ & $\%$ slgD \\
\hline 1 & 80 & M & 0 & 25,000 & 77.0 & Mutated & NEG & 90 & NEG & NEG & NEG & - & NEG \\
\hline 2 & 71 & $\mathrm{~F}$ & 0 & 29,600 & 81.0 & ND & NEG & 90 & NEG & 69 & 42 & 4.5 & NEG \\
\hline 3 & 48 & $\mathrm{~F}$ & I & 81,500 & 80.4 & Mutated & NEG & 97 & NEG & 15 & NEG & - & NEG \\
\hline 4 & 61 & $\mathrm{~F}$ & I & 72,600 & 94.5 & Mutated & POS & 95 & NEG & 27 & NEG & - & 51 \\
\hline 5 & 69 & $\mathrm{~F}$ & I & 61,500 & 96.5 & ND & NEG & 81 & NEG & 67 & 31 & 4.4 & NEG \\
\hline 6 & 65 & M & I & 53,000 & 85.0 & Mutated & POS & 90 & 52 & 66 & 53 & 11.8 & 57 \\
\hline 7 & 67 & $\mathrm{~F}$ & I & 74,300 & 65.8 & Mutated & NEG & 93 & NEG & 49 & 80 & 15.8 & 84 \\
\hline 8 & 71 & M & I & 89,900 & 90.5 & Mutated & NEG & 91 & 85 & 90 & 90 & 76.3 & 90 \\
\hline 9 & 76 & M & I & 18,300 & 75.0 & Mutated & NEG & 90 & NEG & 15 & 42 & 6.4 & NEG \\
\hline 10 & 61 & M & I & 23,200 & 74.5 & ND & POS & 85 & NEG & 22 & 25 & 2.1 & NEG \\
\hline 11 & 61 & $\mathrm{~F}$ & I & 28,900 & 90.0 & Unmutated & POS & 89 & 12 & 78 & 29 & 2.8 & 31 \\
\hline 12 & 48 & $M$ & I & 26,100 & 93.0 & Mutated & NEG & 87 & 78 & 14 & 33 & 3.4 & 99 \\
\hline 13 & 64 & $\mathrm{~F}$ & I & 23,000 & 75.0 & Mutated & NEG & 89 & NEG & NEG & NEG & - & 14 \\
\hline 14 & 61 & M & I & 80,000 & 95.0 & Unmutated & POS & 90 & 96 & 91 & NEG & - & NEG \\
\hline 15 & 60 & $\mathrm{M}$ & I & 74,400 & 96.0 & Mutated & POS & 77 & NEG & NEG & 34 & 3.6 & 88 \\
\hline 16 & 75 & M & II & 203,300 & 93.0 & Unmutated & POS & 92 & 31 & 94 & 39 & 5.9 & 38 \\
\hline 17 & 72 & $\mathrm{M}$ & II & 98,700 & 89.2 & Unmutated & POS & 91 & 78 & 66 & 23 & 8.0 & 22 \\
\hline 18 & 42 & M & II & 95,300 & 90.9 & Unmutated & POS & 90 & 71 & 51 & 28 & 8.5 & 80 \\
\hline 19 & 76 & $\mathrm{M}$ & ॥ & 37,700 & 79.6 & ND & POS & 92 & 46 & 82 & 34 & 6.7 & 90 \\
\hline 20 & 60 & $\mathrm{M}$ & II & 33,900 & 81.3 & Mutated & NEG & 91 & NEG & 41 & NEG & - & 20 \\
\hline 21 & 77 & $\mathrm{M}$ & II & 24,500 & 79.3 & ND & ND & 94 & NEG & 52 & 89 & 16.6 & 83 \\
\hline 22 & 43 & $\mathrm{~F}$ & II & 129,000 & 91.0 & Unmutated & POS & 90 & 21 & 80 & 75 & 10.5 & 92 \\
\hline 23 & 57 & $\mathrm{~F}$ & II & 102,000 & 93.0 & ND & NEG & 99 & NEG & 83 & 85 & 11.3 & 87 \\
\hline 24 & 74 & M & II & 80,000 & 88.3 & Unmutated & POS & 90 & 24 & 28 & 85 & 11.4 & 83 \\
\hline 25 & 83 & $\mathrm{~F}$ & ॥ & 31,100 & 80.4 & Unmutated & POS & 87 & 48 & 45 & 33 & 3.1 & 38 \\
\hline 26 & 78 & M & II & 29,000 & 80.0 & Mutated & NEG & 82 & NEG & 42 & 82 & 10.8 & NEG \\
\hline 27 & 81 & $\mathrm{M}$ & ॥ & 34,500 & 81.0 & Unmutated & ND & 83 & 52 & 51 & NEG & - & 30 \\
\hline 28 & 56 & $\mathrm{M}$ & III & 128,700 & 96.4 & Unmutated & POS & 94 & 54 & 56 & NEG & - & 63 \\
\hline 29 & 58 & $\mathrm{~F}$ & III & 164,300 & 97.3 & Unmutated & POS & 98 & 58 & 94 & 97 & 204 & 97 \\
\hline 30 & 73 & $\mathrm{~F}$ & III & 20,400 & 85.1 & Unmutated & POS & 85 & 55 & 42 & 75 & 38.7 & 39 \\
\hline 31 & 74 & M & III & 322,000 & 94.0 & Unmutated & POS & 98 & 91 & NEG & 87 & 30.0 & NEG \\
\hline 32 & 71 & $\mathrm{~F}$ & III & 39,900 & 93.0 & Unmutated & POS & 91 & 60 & NEG & NEG & - & NEG \\
\hline 33 & 70 & $\mathrm{~F}$ & III & 264,700 & 96.0 & Unmutated & POS & 98 & 56 & NEG & 33 & 3.0 & 70 \\
\hline 34 & 75 & M & IV & 253,800 & 74.7 & Unmutated & POS & 90 & NEG & 91 & NEG & - & 70 \\
\hline 35 & 77 & $\mathrm{M}$ & IV & 56,200 & 89.6 & Mutated & POS & 92 & NEG & 74 & NEG & - & 72 \\
\hline 36 & 59 & $\mathrm{~F}$ & IV & 159,000 & 79.1 & Unmutated & ND & 92 & NEG & 41 & NEG & - & 29 \\
\hline 37 & 76 & $\mathrm{M}$ & IV & 176,700 & 95.2 & Unmutated & POS & 80 & 68 & 92 & NEG & - & 84 \\
\hline 38 & 76 & $\mathrm{M}$ & IV & 114,000 & 94.9 & Unmutated & POS & 98 & 76 & 82 & NEG & - & 59 \\
\hline 39 & 68 & $\mathrm{~F}$ & IV & 53,400 & 90.4 & Unmutated & POS & 90 & 47 & 38 & 48 & 4.8 & 40 \\
\hline 40 & 66 & $\mathrm{~F}$ & IV & 45,400 & 85.4 & Unmutated & POS & 93 & 52 & 34 & 36 & 2.3 & 42 \\
\hline
\end{tabular}

AStaging system developed by K.R. Rai (54). B"Mutated" was defined as having a frequency of mutations greater than $2 \%$ from germline VH sequence. ${ }^{C}$ As determined by immunoblot analysis on purified B cells (purity at least 98\%). ND, not determined; NEG, negative; POS, positive; slgM, surface IgM; MFI, mean fluorescence intensity.

anti-Lck antibodies (data not shown) supports the hypothesis that Lyn is the Src kinase responsible for the anomalous B-CLL cellular tyrosine phosphorylation.

To validate the presence of the activated conformation of Lyn in freshly prepared CLL B cells, we analyzed the enzyme responsiveness to BCR engagement upon IgM ligation in 15 patients. Figure 4B shows the Lyn activity detected after BCR ligation of B lymphocytes obtained from 1 normal subject and 2 CLL patients, 1 typical patient (CLL no. 18) expressing low levels of IgM and 1 unusual case (CLL no. 29) expressing high IgM levels. Whereas IgM ligation triggered, as expected, a marked activation of Lyn (9.2-fold) in normal B cells, a poor increase in the tyrosine kinase activity was observed in leukemic cells from both patients with respect to the baseline value. Because IgM was highly expressed in normal B lymphocytes as well as in leukemic cells from patient CLL no. 29, the low Lyn activity responsiveness to IgM ligation supports the view that most of Lyn is constitutively active in resting leukemic cells and is poorly dependent on BCR engagement.

Anomalous subcellular localization of Lyn in CLL B cells. Because Lyn protein was highly overexpressed in CLL B cells, we analyzed the subcellular localization of the tyrosine kinase in normal and leukemic B lymphocytes by means of differential ultracentrifugation. To this purpose, cells were sonicated in isotonic buffer, and cytosol and microsomes (II particulate) were separated from the other subcellular fractions (I particulate). Lyn, which is anchored to 
A

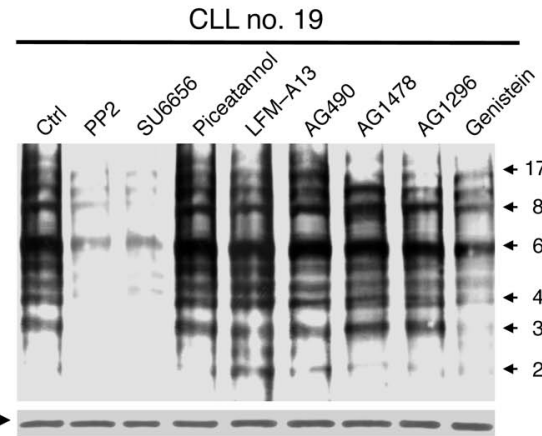

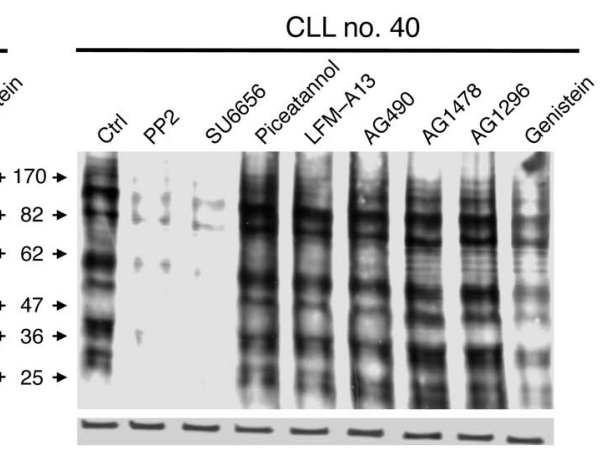

B

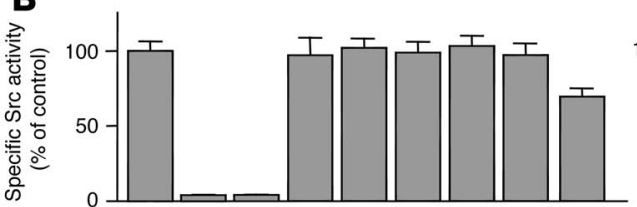

C

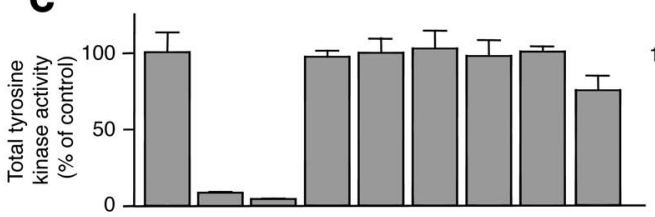

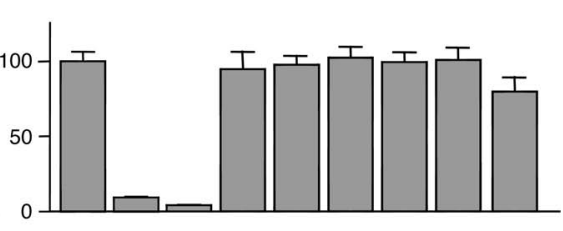

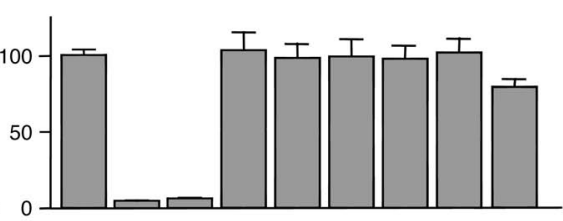

\section{Figure 2}

Effect of several inhibitors on CLL cellular tyrosine phosphorylation and tyrosine kinase activities. Freshly isolated $B$ cells obtained from CLL patients no. 19 and no. 40 were cultured for 15 minutes without or with the indicated tyrosine kinase inhibitors. (A) Cells were lysed and analyzed by immunostaining with antibody against phosphorylated tyrosine as in Figure 1. The molecular mass $(\mathrm{kDa})$ of protein standards is indicated in the center. (B and $\mathbf{C}$ ) Cells were lysed, and the tyrosine kinase activity was detected either on the Src-specific peptide substrate cdc2(6-20) (B) or on the nonspecific random polymer polyGlu 4 Tyr (C). The data are representative of experiments performed with 8 different B-CLL samples. Ctrl, control. the membranes, was only particulated and mostly detected in the microsomal fraction of normal B cells, but a substantial aliquot of both enzyme isoforms (approximately 30\% of the total protein) was also found in the cytosol of all of the 14 leukemic samples examined (Figure 5A, upper panels). Moreover, whereas the enzyme was downregulated in normal cells, both microsomal and cytosolic Lyn isolated from freshly prepared CLL B cells were constitutively active (Figure 5A, lower panels).

Because Lyn is concentrated in membrane subdomains called lipid rafts in resting B lymphocytes $(32,33)$, we investigated the microscopic distribution of Lyn on the plasma membrane of malignant cells. Figure 5B shows that the majority of Lyn was indeed resident in lipid rafts in normal B cells as judged by its colocalization with GM1 ganglioside. In contrast, Lyn was uniformly distributed all over the cell surface in leukemic lymphocytes.

To assess whether mutation(s) of the Lyn protein could be responsible for the anomalous properties of the tyrosine kinase in CLL B cells, we sequenced the Lyn cDNA of four CLL

\section{Figure 3}

Expression of Src kinase proteins and Lyn mRNA in normal and CLL $B$ cells. (A) Immunoblot analysis of the cellular protein level of different Src kinases. The lysates obtained from normal B lymphocytes and leukemic B cells from CLL patients were analyzed by immunostaining with antibodies against the indicated Src kinases. Blots were reprobed with anti- $\beta$-actin antibody as loading control (the reprobing of the Lyn blot is shown). The panel is representative of Lyn analysis performed with 3 different tonsils, 5 peripheral blood samples, and 40 B-CLL samples. The analysis of the other Src kinases was performed with $10 \mathrm{CLL}$ samples. (B) The analysis of Lyn immunolocalization was performed by confocal microscopy in 3 different normal and 10 B-CLL samples. Original magnification, $\times 60$. (C) The analysis of Lyn and $\beta$-actin mRNA expression was performed by Northern blotting in $16 \mathrm{~B}-\mathrm{CLL}$ samples and the same normal $B$ cells shown in $A$. Data from 8 representative B-CLL patients are shown. patients. No mutation in the Lyn sequence was observed in the leukemic cells as compared with the normal cDNA sequence (data not shown).

Lyn is involved in the defective apoptosis of leukemic cells. Next we addressed the question of whether the upregulation of Lyn expression and activity plays a role in the defective apoptosis of

A

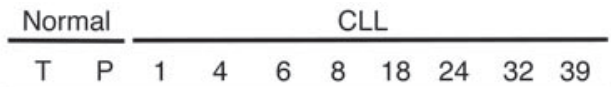

Wb Lyn $\mathrm{Lar}$

Wb Fyn - - - - - - - - -

Wb Fgr $+=\ldots+\cdots+\cdots+\cdots$

Wb Lck

Wb $\beta$-actin $-m-m-\infty-\cdots$

B

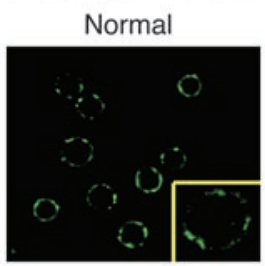

CLL

C

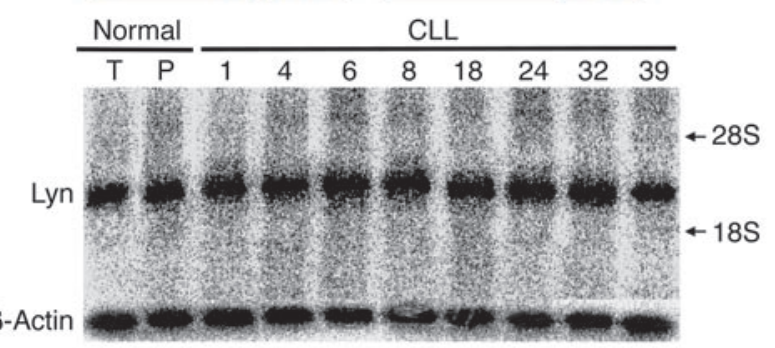


A

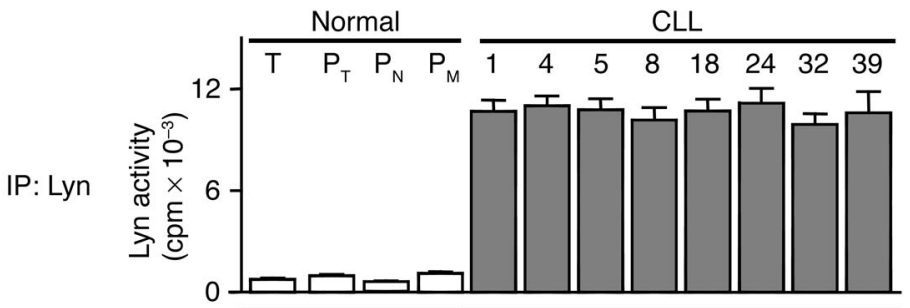

B
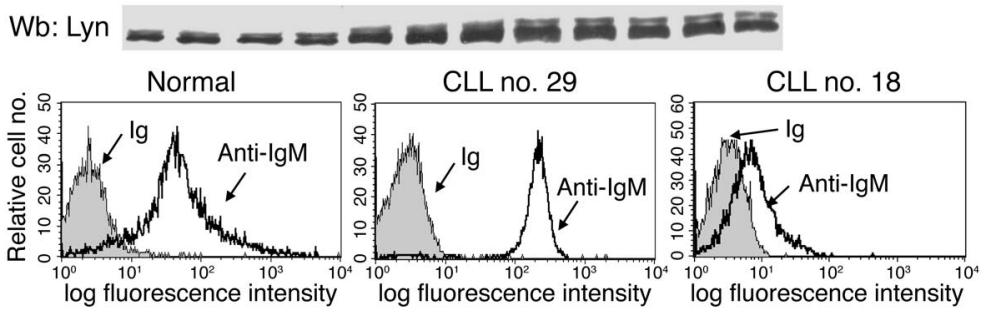

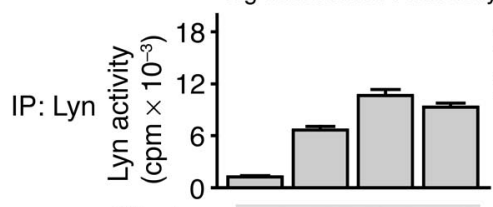

Wb: Lyn

Stimulation (min)
18
6
6
0

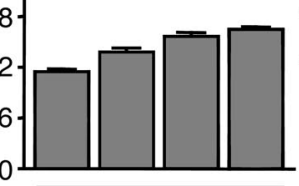

$\underset{0}{5} \quad \underset{10}{15}$
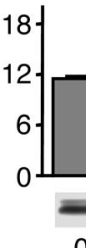

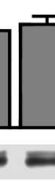

0

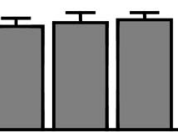

$5 \quad 10 \quad 15$

\section{Figure 4}

Kinase activity of Lyn in normal and CLL B cells before and after IgM ligation. (A) Analysis of Lyn activity in unstimulated $B$ cells. Normal cells refer to tonsil $(T)$, total peripheral blood $B$ cells $\left(P_{T}\right)$, naive peripheral blood $B$ lymphocytes $\left(P_{N}\right)$, and memory peripheral blood $B$ lymphocytes $\left(P_{M}\right)$. Normal and leukemic B cells from CLL patients were lysed and Lyn was immunoprecipitated. The immunocomplexes were then analyzed for both the in vitro kinase activity tested toward the Src-specific peptide substrate cdc2(6-20) and anti-Lyn immunostaining. The data are representative of experiments performed with 3 different tonsils, 5 peripheral blood samples, and 40 B-CLL samples. (B) Analysis of Lyn activity in B cells after IgM ligation. B lymphocytes were isolated from 1 healthy donor and 2 CLL patients, 1 (CLL no. 29) expressing high levels and 1 (CLL no. 18) expressing low levels of $\operatorname{lgM}$, as indicated by flow cytometry analysis (upper panels). B cells were incubated with anti-human IgM $(20 \mu \mathrm{g} / \mathrm{ml})$ at $37^{\circ} \mathrm{C}$ for the indicated times and the kinase activity of anti-Lyn immunoprecipitates was detected as described in $\mathbf{A}$ (lower panels). The data are representative of 3 separate experiments. leukemic cells. To this purpose, we investigated the relationship between Lyn and the cell survival of malignant lymphocytes in different experimental conditions. We analyzed leukemic cells cultured either with dexamethazone (Dex) and cyclosporin A (CsA), which are known to induce apoptosis of human lymphocytes $(34,35)$, or with PP2 and SU6656, which are selective inhibitors of Lyn (21). In preliminary experiments, the dose response of the B-CLL cell cultures to the different compounds was analyzed and the concentration required to induce death in $50 \%$ of leukemic cells $\left(\mathrm{IC}_{50}\right)$ was determined. The $\mathrm{IC}_{50}$ values for PP2, SU6656, EGCG, CsA, and Dex were $10 \mu \mathrm{M}, 7.5 \mu \mathrm{M}$, $10 \mu \mathrm{M}, 7 \mu \mathrm{M}$, and $10 \mu \mathrm{M}$, respectively. The results obtained with 1 representative CLL sample are reported in Figure 6. When leukemic cells were cultured in the presence of CsA or Dex, a marked increase in apoptosis was observed as compared with cells

\section{Figure 5}

Subcellular localization of Lyn in normal and CLL B cells. (A) Analysis by differential ultracentrifugation. $B$ cells were sonicated in isotonic buffer and cytosol, and microsomes (II particulate fraction, II-P) were separated from the cell debris and the other cellular particles (I particulate fraction, I-P) by ultracentrifugation. Comparable aliquots of the different fractions were loaded on SDS/PAGE and the separated proteins were immunostained with either anti-Lyn antibody or the antibodies specific for the indicated distribution control markers: complex II (I particulate, mitochondria), SERCA2 (II particulate, endoplasmic reticulum), and CD79b (II particulate, plasma membrane). Other aliquots were immunoprecipitated with anti-Lyn antibody, and the kinase activity of the immunocomplexes was detected in vitro. The data are representative of experiments performed with 3 different normal and 14 B-CLL samples. (B) Confocal microscopic analysis of the ganglioside GM1 labeled with cholera toxin B subunit (Texas Red) and Lyn (FITC) in normal and leukemic B lymphocytes. The data are representative of experiments performed with 5 normal and 10 different leukemic samples. Original magnification, $\times 60$. cultured in medium alone, as demonstrated by annexin $\mathrm{V}$ staining (Figure 6) and caspase activation (Figure 7A) analyses. Interestingly, leukemic cell apoptosis correlated with a great decrease in both basal activity and amount of Lyn (Figure 7B). Exposure of leukemic cells to PP2 and SU6656 caused both the expected

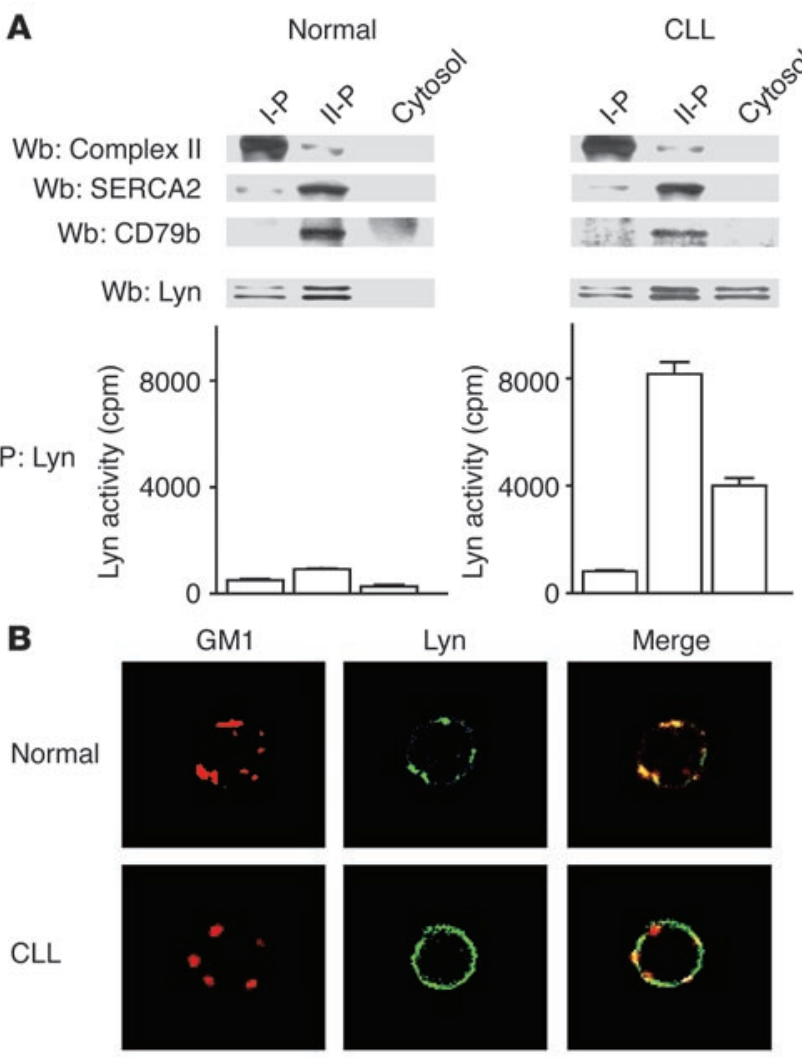



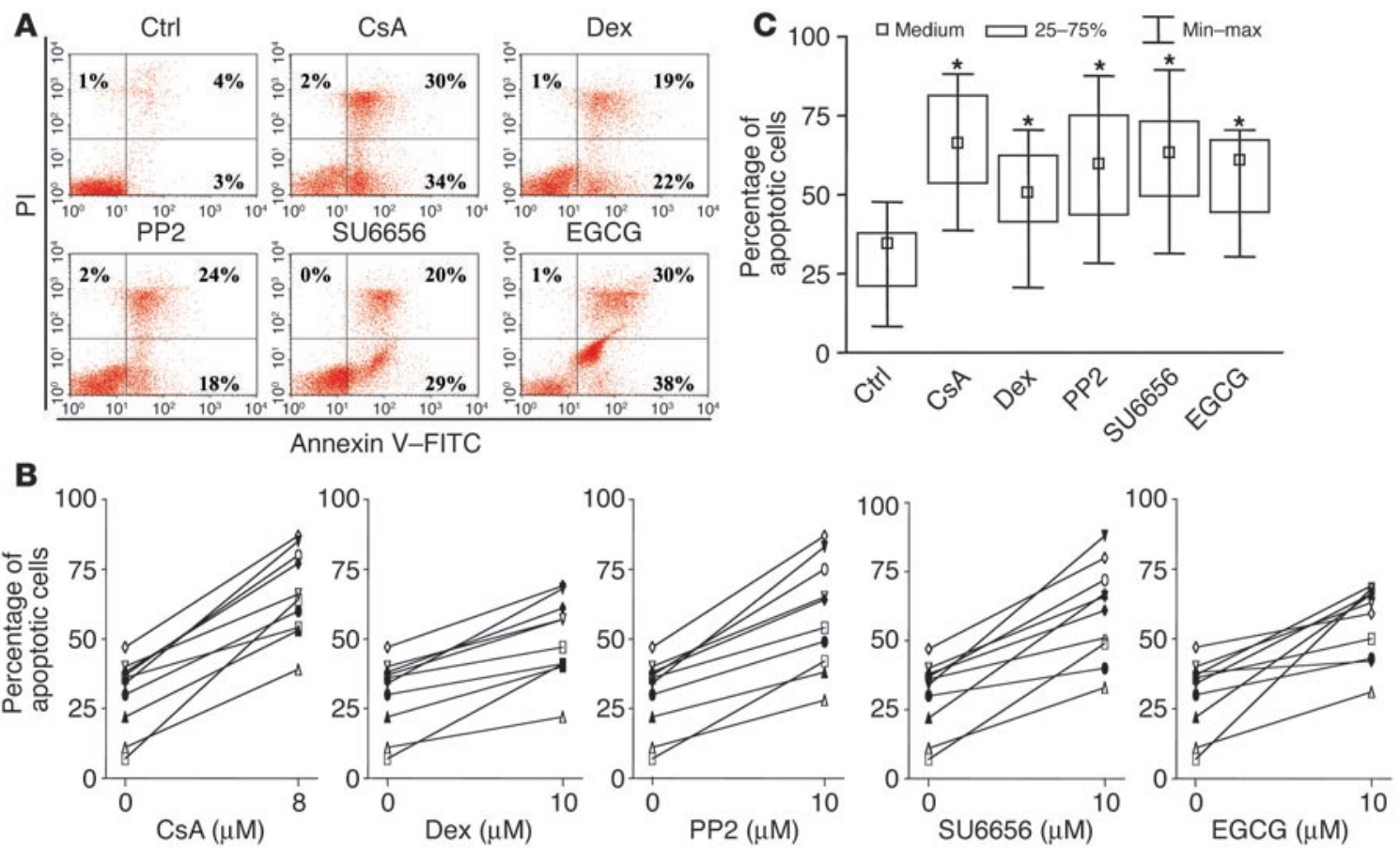

Figure 6

Effect of different compounds on the apoptosis of CLL B cells. Leukemic cells were cultured for 24 hours alone or in the presence of CsA $(8 \mu \mathrm{M})$, Dex $(10 \mu \mathrm{M})$, PP2 $(10 \mu \mathrm{M})$, SU6656 $(10 \mu \mathrm{M})$, or EGCG $(10 \mu \mathrm{M})$, and cell apoptosis was analyzed by annexin V-PI flow cytometry. (A) Flow cytometry analysis of B-CLL sample no. 14. (B) Percentage of apoptotic cells obtained in the different conditions with the following B-CLL samples: no. 2 (filled inverted triangles), no. 4 (open inverted triangles), no. 6 (filled triangles), no. 9 (open circles), no. 14 (filled squares), no. 17 (filled circles), no. 28 (filled diamonds), no. 33 (arrows), no. 35 (open triangles), and no. 39 (open squares). (C) The data are reported as median, lower and upper quartile, and minimum and maximum. ${ }^{*} P<0.005$ compared with cells cultured in medium alone (Ctrl). Min-max, minimum-maximum.

inhibition of the overexpressed Lyn activity (Figure 7B) and marked cell apoptosis (Figures 6 and 7A). To confirm the specific involvement of Lyn in cell apoptosis, we performed control experiments using PP3, an inactive analog of PP2. Its addition in cell cultures did not induce Lyn inhibition or cell apoptosis (data not shown). The green tea constituent epigallocatechin3-gallate (EGCG) acts as a cancer-preventive agent because of its remarkable ability to induce apoptosis in cancer cells by caspase activation (36). Because we have recently shown that EGCG inhibits Lyn both in vitro and in cells (37), we analyzed the effect of this catechin on B-CLL cell cultures. The induced cell apoptosis (Figures 6 and 7A) and the tyrosine kinase inhibition (Figure 7B) caused by the presence of EGCG confirm the relationship between high Lyn activity and abnormal survival and accumulation of these leukemic cells.

\section{Figure 7}

Effect of different compounds on caspase and Lyn activities of CLL B cells. Leukemic lymphocytes were cultured without or with drugs as described in Figure 6. (A) Caspase activity was analyzed by Western blotting with an antibody against PARP protein, a caspase substrate. The arrows indicate the position of the full-length protein (116 kDa) and its cleaved fragment (89 kDa). (B) Leukemic cells were lysed and Lyn was immunoprecipitated. The immunocomplexes were then analyzed for both in vitro kinase activity and anti-Lyn immunostaining. The data, relative to sample no. 14, are representative of experiments performed with the same B-CLL samples analyzed in Figure 6B.

\section{Discussion}

This study was designed to investigate the molecular determinants that are responsible for the prolonged survival and accumulation of leukemic cells in patients with B-CLL. To address this question, we analyzed the Src kinase Lyn, a protein that plays a crucial role in transducing survival or apoptosis signals following BCR triggering. The analysis of malignant B lymphocytes obtained from the peripheral blood of 40 CLL patients demonstrated that the tyrosine kinase Lyn displays anomalous properties that contribute to the pathology of these leukemic cells.

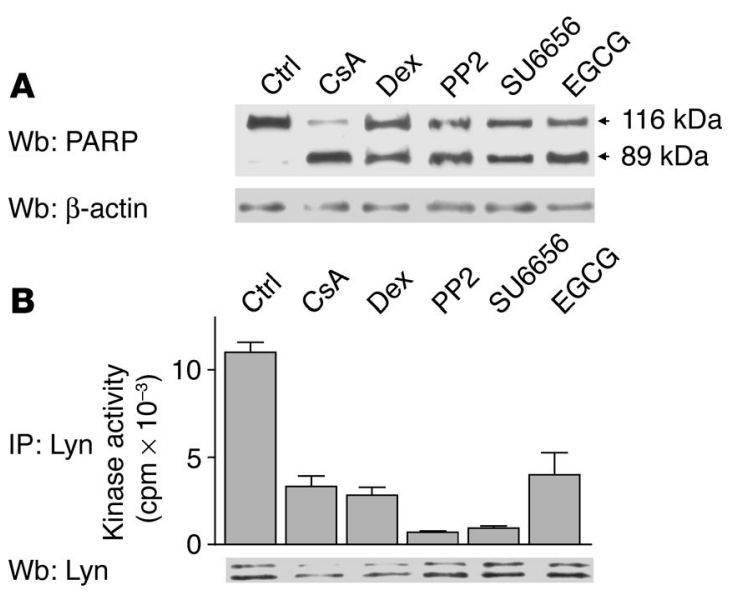


In particular, we found that Lyn expression detected in freshly isolated leukemic cells obtained from all CLL patients were 2.5to 5-fold higher than in normal B lymphocytes, suggesting that the overexpression of this protein represents a peculiar property of these malignant cells. The evidence that Lyn mRNA level was comparable in normal and neoplastic B cells demonstrates that the anomalous protein expression was not related to differences in gene transcription and/or mRNA stability. A possible hypothesis to explain the different Lyn protein expression between leukemic and normal B cells might be represented by a deregulation in protein turnover. In this context, the defective apoptosis of B-CLL lymphocytes has been related to a deregulation of the ubiquitinproteasome system pathway (38), which has been claimed to account for Lyn degradation (39).

By means of confocal microscopy and differential ultracentrifugation analyses, we observed that Lyn protein was abnormally distributed in malignant cells as compared with normal B cells, in 2 main respects. First, the immunolocalization at the plasma membrane of leukemic cells appeared more intense and coalescent, consistent with a different distribution of Lyn across the membrane subdomains; whereas Lyn was concentrated in membrane lipid rafts in normal B cells, the enzyme was present all over the cell surface membrane in leukemic cells. Second, the tyrosine kinase was also detected in the cytosol of the malignant B cells. The release of Lyn into the cytosol following caspase-dependent cleavage of the tyrosine kinase at its $\mathrm{N}$ terminus has been described as a general mechanism in hematopoietic cells during BCR-induced apoptosis (40). In contrast, the cytosolic localization of Lyn in unstimulated cells is a property unique to freshly isolated B-CLL malignant lymphocytes. Our analyses demonstrated that both Lyn isoforms were resident in the soluble fraction of the leukemic cells. Moreover, the finding that the Lyn c-DNA of 4 CLL patients did not contain any mutation(s) compared to the sequence of the normal enzyme (data not shown) ruled out the hypothesis that genetic alteration might be responsible for the anomalous properties of Lyn. Whether the defective N-terminal myristylation/palmitoylation of the kinase or merely the exceedingly high kinase concentration is responsible for the generation of soluble Lyn remains an open question. It is noteworthy that the cleaved form of Lyn generated by caspases and relocated to the cytosol during BCR-induced cell death acts as a negative regulator of apoptosis in the B lymphoma cell line (41). The findings that CLL B cells contained a cytosolic Lyn fraction and were defective in programmed cell death suggest that the tyrosine phosphorylation of specific cytosolic targets might account, at least in part, for cell resistance to apoptosis.

The activity of Lyn is critically regulated through its C-terminal Tyr507, which is phosphorylated by the tyrosine kinase Csk and dephosphorylated by the receptor tyrosine phosphatase CD45. In resting $\mathrm{B}$ lymphocytes, Lyn is present in its inactive conformation, a result of Csk phosphorylation of Tyr507, which gives rise to an intramolecular association of the phosphorylated residue with Lyn's own SH2 domain (42-44). Analysis of the Lyn activation state in freshly isolated leukemic cells from CLL patients showed that most membrane and soluble enzyme displayed a constitutive activity that was independent of BCR engagement. This finding accounts for the abnormally high basal tyrosine phosphorylation observed in these cells, which was completely abrogated by the highly selective Src inhibitors PP2 and SU6656 and unaffected by inhibitors selective for other receptor and nonreceptor tyrosine kinases. Because Csk, unlike Lyn, was similarly expressed in normal and CLL B cells (data not shown), the constitutive activity of Lyn could be due to the fact that the amount of Csk is insufficient to phosphorylate and downregulate the overexpressed Lyn substrate. However, it is likely that other factors are responsible for the presence of the active form of Lyn in freshly prepared CLL B cells, first among which might be the dephosphorylation of Lyn phosphorylated at Tyr507 by the tyrosine phosphatase CD45, an abundant membrane protein that, in normal B cells, has access to Lyn only after its migration to lipid rafts induced by BCR engagement (32). Furthermore, the high concentration of the Lyn protein in CLL B cells could promote the kinase intermolecular autophosphorylation at Tyr396, which in turn induces Lyn activation $(29,43)$.

In normal B lymphocytes, BCR engagement triggers a great increase in Lyn activity compared with the low baseline levels. By contrast, in leukemic cells from B-CLL patients, the basal Lyn activity was already high, and IgM ligation induced only a slight increase in the kinase activity. The finding that Lyn was constitutively active in these cells independently of BCR engagement might suggest that upregulated Lyn is partially unrelated to BCR signaling. Because Ig expression is anomalous in CLL cells, an alternative explanation rests on a constitutive BCR activation ongoing in the leukemic cells due to Ig autoreactivity. In any event, the constitutive Lyn activation in B-CLL correlates with extended cell survival and defective apoptosis even in the absence of specific stimuli. In fact, the inhibition of Lyn activity obtained by treating the leukemic cells with specific inhibitors of the tyrosine kinase is sufficient to restore cell apoptosis, providing a correlation between high basal Lyn activity and defects in the induction of the programmed cell death in CLL B cells. This finding is validated by treatment of CLL B cells with Dex, CsA, and EGCG, which strongly decreased the basal activity of Lyn and increased leukemic cell apoptosis, suggesting that the apoptotic effect of these drugs is mediated by Lyn downregulation. Our hypothesis is also consistent with other reports showing that either Lyn activation in hematopoietic cell lineages (45-47) or active Lyn overexpression in epithelial cells plays a crucial role in preventing cell apoptosis (48). Accordingly, a 3-fold increase in apoptotic preB cells was observed in mice deficient in the expression of the Src kinases Lyn, Fyn, and Blk as compared with wild-type mice (49). These data might have clinical relevance because they identify the Src kinase Lyn as a potential target for drugs capable of inducing apoptosis in B-CLL leukemic cells.

\section{Methods}

Patients, cell separation, and culture conditions. After obtaining their informed consent, we obtained peripheral blood from 40 untreated patients diagnosed with B-CLL as confirmed by clinical, pathologic, and flow cytometry criteria (1). Patient characteristics are reported in Table 1. PBMCs of the patients were isolated by density-gradient centrifugation over Ficoll-Hypaque, as previously reported (50). B cells were purified from PBMCs by removing $\mathrm{T}$ cells by rosetting method with sheep erythrocytes and monocytes by adherence to plastic surfaces, as previously reported (51). As assessed by flow cytometry, the content of $\mathrm{CD} 19^{+} \mathrm{B}$ cells was greater than $95 \%$ in all samples.

Untouched peripheral blood B cells were isolated from PBMCs of 5 normal donors by negative selection using a B cell isolation kit and MACS separation columns (Milteny Biotec). Purified tonsillar B cells 
were obtained from 3 tonsils as previously described (52). The purity of the obtained peripheral blood and tonsillar B cells was at least $95 \%$ $\left(\mathrm{CD} 19^{+}\right)$, as assessed by flow cytometry. For selected experiments, peripheral blood B cells were enriched for naive and memory B cells according to their reactivity to CD27. Briefly, purified peripheral blood B lymphocytes were incubated with CD27 MicroBeads (Milteny Biotec) and were fractionated into $\mathrm{CD} 19^{+} / \mathrm{CD} 27^{+}$(memory B cells) and $\mathrm{CD} 19^{+} /$ CD27- (naive B cells), with a purity greater than $98 \%$.

Purified B cells $\left(2 \times 10^{6}\right.$ cells $\left./ \mathrm{ml}\right)$ were cultured in RPMI- 1640 medium (Sigma-Aldrich) supplemented with $10 \%$ heated inactivated fetal calf serum (ICN Flow), $2 \mathrm{mM}$ L-glutamine, $100 \mathrm{U} / \mathrm{ml}$ penicillin, and $100 \mu \mathrm{g} / \mathrm{ml}$ streptomycin in 24 -well plates (Costar), at $37^{\circ} \mathrm{C}$ in a humidified atmosphere containing $5 \% \mathrm{CO}_{2}$. In a different experiment, cells were incubated several times without or with goat anti-human $\operatorname{IgM~F}\left(\mathrm{ab}^{\prime}\right)_{2}(10 \mu \mathrm{g} / \mathrm{ml})$ (Caltag Laboratories).

Analysis of cellular tyrosine phosphorylation and tyrosine kinase activity. Cells $\left(5 \times 10^{5}\right.$ for each assay) were preincubated for 15 minutes in the absence or presence of PP2 $(7.5 \mu \mathrm{M})$, SU6656 $(7.5 \mu \mathrm{M})$, piceatannol $(15 \mu \mathrm{M})$, LFM-A13 $(20 \mu \mathrm{M})$, AG490 $(20 \mu \mathrm{M})$, AG1296 $(20 \mu \mathrm{M})$, AG1478 $(20 \mu \mathrm{M})$, or genistein $(20 \mu \mathrm{M})($ Calbiochem). Cells were resuspended and rapidly lysed in buffer A (62 mM Tris/HCl buffer, $\mathrm{pH} 6.8$, containing 5\% glycerol, $0.5 \% \mathrm{SDS}$, and $0.5 \% \beta$-mercaptoethanol). Samples were then subjected to SDS/PAGE (10\% gels), transferred to nitrocellulose membranes, and immunostained with anti-phosphotyrosine (PY-20) monoclonal antibody (ICN Biotechnology) using an enhanced chemiluminescent detection system (ECL; Amersham Pharmacia Biotech).

To analyze cellular tyrosine kinase activity, cells $\left(4 \times 10^{5}\right.$ for each assay), preincubated with or without tyrosine kinase inhibitors as described above, were lysed by adding $0.5 \%$ Triton X-100 and phosphatase and protease inhibitor cocktails in a $25-\mu \mathrm{l}$ volume for 15 minutes. The tyrosine kinase activity was then tested in $50 \mu \mathrm{l}$ of phosphorylation medium containing $50 \mathrm{mM}$ Tris/ $\mathrm{HCl}, \mathrm{pH} 7.5,10 \mathrm{mM} \mathrm{MnCl} 2,30 \mu \mathrm{M}\left[\gamma^{32} \mathrm{P}\right]$ ATP (Amersham Pharmacia Biotech) (specific activity 1,000 cpm/pmol), $200 \mu \mathrm{M}$ sodium orthovanadate, and either $1 \mathrm{mg} / \mathrm{ml}$ random polymer polyGlu $\mathrm{T}_{4} \mathrm{Tyr}$ (SigmaAldrich) or $200 \mu \mathrm{M} \mathrm{cdc}$ (6-20) peptide (29) (kindly provided by O. Marin, University of Padova, Padova, Italy) used as exogenous substrates. After 10 minutes of incubation at $30^{\circ} \mathrm{C}$, the reactions were stopped and the samples were loaded on SDS/PAGE. Substrate ${ }^{32} \mathrm{P}$-phosphorylation was quantified on a Packard InstantImager.

Analysis of cellular Src kinase expression. Cells were lysed and immunostained with anti-Lyn, anti-Src, anti-Fyn, anti-c-Fgr, and antiLck antibodies (Santa Cruz Biotechnology) as described above. The blots were then stripped and reprobed with $\beta$-actin antibody (Santa Cruz Biotechnology). The protein expression of the Src kinases was quantified by densitometric analysis using an ImagerMaster VDS instruments (Amersham Pharmacia Biotech).

$I P$ and in vitro kinase activity of different Src kinases. In order to analyze total cellular activity of the different Src kinases, cells $\left(2 \times 10^{6}\right.$ for each assay) were resuspended and lysed for 1 hour at $4^{\circ} \mathrm{C}$ in $450 \mu \mathrm{l}$ of buffer B containing $20 \mathrm{mM}$ Tris $/ \mathrm{HCl}, \mathrm{pH} 7.5,10 \%$ glycerol, $1 \%$ Triton $\mathrm{X}-100,1 \mathrm{mM}$ EDTA, $50 \mathrm{mM} \mathrm{NaCl}, 1 \mathrm{mM}$ sodium orthovanadate, and protease inhibitor cocktail. After centrifugation, the supernatants were incubated for 2 hours at $4{ }^{\circ} \mathrm{C}$ with the appropriate Src kinase antibody bound to protein A-Sepharose. The immunocomplexes were washed 3 times by centrifugation and resuspended in buffer $\mathrm{C}(50 \mathrm{mM}$ Tris/ $\mathrm{HCl}$, $\mathrm{pH} 7.5$, containing phosphatases and protease inhibitor cocktails). The pellets were solubilized in $30 \mu \mathrm{l}$ of buffer $\mathrm{C}$ for kinase activity, and, as a control, $5 \mu \mathrm{l}$ were supplemented with $20 \mu \mathrm{l}$ of buffer A lacking $\beta$-mercaptoethanol, loaded on SDS/PAGE, and immunostained with the appropriate Src kinase antibody.
To test the kinase activity of IP, $20 \mu \mathrm{l}$ of immunocomplexes were incubated in $30 \mu \mathrm{l}$ of the phosphorylation medium described above using 200 $\mu \mathrm{M} \mathrm{cdc2(6-20)}$ peptide as a substrate. After 10 minutes of incubation at $30^{\circ} \mathrm{C}$, the samples were loaded on SDS/PAGE and analyzed for both peptide ${ }^{32} \mathrm{P}$-phosphorylation (see above) and immunostaining with the appropriate Src kinase antibody.

Lyn subcellular localization. Approximately $4 \times 10^{6}$ cells were sonicated in $400 \mu \mathrm{l}$ of isotonic buffer containing $50 \mathrm{mM}$ Tris/ $\mathrm{HCl}(\mathrm{pH} 7.5), 0.25 \mathrm{M}$ saccharose, $1 \mathrm{mM}$ orthovanadate, and protease inhibitor cocktail (Boehringer) and centrifuged at $10,000 \mathrm{~g}$ for 10 minutes in order to separate the particulate fraction containing cell debris, nuclei, and other cellular particles (pellet I). The supernatant was further centrifuged at $100,000 \mathrm{~g}$ for 1 hour to separate the cytosol from the microsomes (pellet II). The pellets were resuspended in $400 \mu \mathrm{l}$ of buffer B, and $20 \mu \mathrm{l}$ of the different fractions were loaded on SDS/PAGE, blotted, and immunostained with either anti-Lyn antibody or the antibodies specific for the following distribution control markers: Complex II (Molecular Probes), SERCA2 (Sarco(endo)plasmic Reticulum Ca ${ }^{2+}$-ATPase) (Affinity Bioreagents), and CD79b (Santa Cruz Biotechnology). The residual amount of the different fractions was used to perform Lyn immunoprecipitation and in vitro kinase assay as described in the previous paragraph.

Flow cytometry analysis. The following monoclonal antibodies were used for direct immunofluorescence staining: CD3-FITC, CD19-FITC (BD), anti-IgM-FITC, anti-IgD-FITC (DAKO), CD5-PE, CD16-PE, CD23-PE, CD38-PE, and CD79b-PE (BD Biosciences - Pharmingen). Cells were scored using a FACScalibur analyzer (BD Biosciences - Immunocytometry Systems) and data processed using the CellQuest software (BD).

Apoptosis assays. B cells, incubated with or without CsA $(8 \mu \mathrm{M}), \operatorname{Dex}(10 \mu \mathrm{M})$ (Sigma-Aldrich), PP2 $(10 \mu \mathrm{M})$, SU6656 $(10 \mu \mathrm{M})$, or EGCG $(10 \mu \mathrm{M})$ (Calbiochem) for 24 hours, were collected by centrifugation and washed once with PBS. Exposure of phosphatidylserine residues was quantified by surface annexin V staining using the protocol outlined in the Bender Kit (Bender Medsystems). A total of $1 \times 10^{6}$ cells were resuspended in $200 \mu \mathrm{l}$ of binding buffer (10 mM HEPES, pH 7.4, $140 \mathrm{mM} \mathrm{NaCl}$, and $5 \mathrm{mM} \mathrm{CaCl}_{2}$ ) and then incubated with $0.5 \mu \mathrm{g} / \mathrm{ml}$ of annexin V-FITC for 15 minutes in the dark. Cells were washed again and resuspended in binding buffer. Then $5 \mu \mathrm{l}(20 \mu \mathrm{g} / \mathrm{ml})$ of propidium iodide (PI) was added to each sample prior to flow cytometric analysis (FACScalibur analyzer; BD Biosciences - Immunocytometry Systems). Ten thousand cells per sample were acquired with the use of CellQuest software (BD), and data were analyzed by plotting on an annexin $\mathrm{V}-\mathrm{PI}$ logarithmic scattergram.

Cleavage of the broad caspase substrate PARP was determined by Western blot analysis. A total of $0.5 \times 10^{6}$ cells were resuspended and rapidly lysed in buffer A (62 mM Tris/HCl, pH 6.8, 5\% glycerol, 0.5\% SDS, and $0.5 \% \beta$-mercaptoethanol). Samples were then subjected to SDS/PAGE (10\% gels), transferred to nitrocellulose membranes, and immunostained with PARP polyclonal antibody (Cell Signaling).

Confocal microscopy analysis. Membrane lipid raft aggregation or patching was performed. B lymphocytes were incubated with unlabeled cholera toxin $\beta$ subunit (Sigma-Aldrich), which binds to the GM1 ganglioside, a component of lipid raft membrane microdomains (53). Following 30 minutes of incubation at room temperature, the cells were washed twice with PBS and were then incubated with rabbit anti-cholera toxin B for 30 minutes. For patching, a third-step incubation with anti-rabbit Texas Red-conjugated for 30 minutes on ice was performed. Then B lymphocytes, at a concentration of $0.4 \times 10^{6} / \mathrm{ml}$, were mounted, in a volume of $50 \mu \mathrm{l} /$ well, on poly-L-lysine-coated slides (Poliscience Inc.). An equal volume of $4 \%$ paraformaldehyde was added for 10 minutes at room temperature to fix the cells. The fixed cells were then washed twice with PBS and permeabilized with $0.1 \%$ Triton X-100 for 4 minutes. Before staining, 
nonspecific protein binding was blocked by incubating slides for 30 minutes in $1 \%$ BSA. Cells were then stained with $1 / 50$ diluted mouse monoclonal IgG2a anti-Lyn (Santa Cruz Biotechnology) for 15 minutes in the dark, washed, and stained with FITC-conjugated secondary Ig (Dako). The specificity of staining was controlled by using isotypecontrol antibodies, followed by the appropriate fluorescent secondary antibodies. Background staining with control antibodies was routinely compared with positively stained cells and was not visible using identical acquisition settings. Slides were mounted with coverslips and fluorescence was detected using a Biorad confocal microscope equipped with a fluorescence filter set for excitation at $488 \mathrm{~nm}$.

RT-PCR analysis of Lyn transcripts. Total RNA was extracted from 4-10 $\times 10^{6}$ purified B cells using the RNeasy Mini Kit (Qiagen), in accordance with the manufacturer's instructions. First-strand cDNA was synthesized from $1 \mu \mathrm{g}$ of total RNA in a total volume of $20 \mu \mathrm{l}$ using oligo(dT) primers and the Promega Reverse Transcription System (Promega Corp.), in accordance with the manufacturer's instructions. For human Lyn, $2 \mu \mathrm{l}$ of cDNA were amplified in a total volume of $50 \mu \mathrm{l}$ in the presence of $20 \mathrm{pM}$ of the following primers: 5'-GGAGGAGCCCATTTACATCATCA-3' and 5'-AGTTCTCCACACGGGGCATCC- $3^{\prime}$. This amplified a band of $470 \mathrm{bp}$. The reaction mixture consisted of $1.5 \mathrm{mM} \mathrm{MgCl}_{2}, 500 \mathrm{mM} \mathrm{KCl}, 200 \mu \mathrm{M}$ dNTPs, and $2.5 \mathrm{U}$ Taq polymerase (Applied Biosystems). Reaction conditions were 1 minute of denaturation at $94^{\circ} \mathrm{C}, 1$ minute of annealing at $66^{\circ} \mathrm{C}$, and 3 minutes of extension at $72^{\circ} \mathrm{C}$ for 25 cycles followed by final extension of 7 minutes at $72^{\circ} \mathrm{C}$. For $\beta$-actin, $2 \mu \mathrm{l}$ of cDNA were amplified in a total volume of $50 \mu \mathrm{l}$ in the presence of $20 \mathrm{pM}$ of the following primers: $5^{\prime}$ GTGGGGCGCCCCAGGCACCA and 5'-GAAATCGTGCGTGACATTAAGGAG- $3^{\prime}$. This amplified a product of $540 \mathrm{bp}$. The reaction mixture was similar to that used for human Lyn. Reaction conditions were 30 seconds of denaturation at $94^{\circ} \mathrm{C}, 30$ seconds of annealing at $57^{\circ} \mathrm{C}$, and 40 seconds of extension of $72^{\circ} \mathrm{C}$ for 25 cycles followed by a final extension of $7 \mathrm{~min}$ utes at $72^{\circ} \mathrm{C}$. Aliquots of PCR products were separated by electrophoresis on $2 \%$ agarose gel and visualized by ethidium bromide staining.

Northern blot analysis of Lyn transcripts. B cell total RNA (15 $\mu \mathrm{g})$ was separated on a $1 \%$ formaldehyde-agarose gel, stained with ethidium bromide, and transferred to a nylon membrane (Hybond- $\mathrm{N}^{+}$, Amersham Pharmacia Biotech) using standard protocols. The membrane was hybridized with ${ }^{32} \mathrm{P}-$ labeled lyn probe derived from RT-PCR amplification product corresponding to nucleotides $1,110-1,859$ in accordance with the standard hybridization protocol. To ensure the quality and quantity of RNA analyzed, the blot was washed and reprobed for $\beta$-actin expression. The density of the bands was analyzed on a Packard InstantImager.

1. Cheson, B.D., et al. 1996. National Cancer Institute-sponsored Working Group guidelines for chronic lymphocytic leukemia: revised guidelines for diagnosis and treatment. Blood. 87:4990-4997.

2. Harris, N.L., et al. 1994. A revised EuropeanAmerican classification of lymphoid neoplasms: a proposal from the international lymphoma study group. Blood. 84:1361-1392.

3. Caligaris-Cappio, F., and Ferrarini, M. 1996. B cells and their fate in health and disease. Immunol. Today. 17:206-208.

4. Hamblin, T.J., and Oscier, D.G. 1997. Chronic lymphocytic leukaemia: the nature of the leukaemic cell. Blood Rev. 11:119-128.

5. Osterborg, A., Mellstedt, H., and Keating, M. 2002. Clinical effects of alemtuzumab (Campath-1H) in B-cell chronic lymphocytic leukemia. Med. Oncol. 19(Suppl.):S21-S26.

6. Montserrat, E. 2003. Rituximab in chronic lymphocytic leukemia. Semin. Oncol. 30:34-39.

7. Mavromatis, B., and Cheson, B.D. 2003. Monoclonal antibody therapy of chronic lymphocytic leukemia.

Sequencing analysis of Lyn cDNA. Total RNA was prepared from purified B cells of 4 patients with B-CLL with the RNeasy Mini kit (Qiagen). One microgram of total RNA was reverse-transcribed to cDNA using the Promega Reverse Transcription System (Promega Corp.). Then, to amplify the entire coding region of the Lyn gene, cDNA was amplified by PCR using the following primer pairs: 5'-GAACTCAAGTCACCGTGGAGC-3' and 5'-TCCGGGTGGATGCCATCATAG-3'; 5'-AGATCCAGAGGAACAAGGAGAC-3' and 5'-CTAATAAGGAAAGCTCCAGCGC-3'; 5'-CGCAGAAAGGCAGCTTTTGGC-3' and 5'-GAGCCTCACGAGCTTGTCATG-3'; and 5'-AGGTGGCTGTGAAAACCCTG-3' and 5'-AAATGGACGGGTCTCCCTGT-3'. Each of the amplified fragments was purified from $2 \%$ agarose gel with QIAquick Gel Extraction Kit (Qiagen), and direct sequencing was carried out using the ABI Prism Big Dye Terminator Cycle Sequencing Kit (Applied Biosystems) and an ABI PRISM 310 DNA Sequencer (Applied Biosystems) with the same primers as used for PCR. All sequencing reactions were performed in both forward and reverse directions. Sequences were compared to the published human Lyn mRNA sequence (GenBank accession number M16038).

Statistical analysis. Statistical analysis was performed using Wilcoxon matched pairs test. Data are reported as median, lower and upper quartile, and minimum and maximum. $P$ values less than 0.05 were considered statistically significant.

\section{Acknowledgments}

The authors wish to thank Martin Donach for his help in the preparation of the manuscript. This work was supported by the Italian Association for Cancer Research, Milan, Italy; Ministero dell'Istruzione, dell'Università e della Ricerca (FIRB-2001 and PRIN2002), Rome, Italy; and the Ministero della Salute, Rome, Italy.

Received for publication May 7, 2004, and accepted in revised form November 9, 2004.

Address correspondence to: Livio Trentin, Università di Padova, Dipartimento di Medicina Clinica e Sperimentale, Immunologia Clinica, Via Giustiniani 2, 35128 Padova, Italy. Phone: 011-39-049821-2298 or 011-39-049-821-2299; Fax: 011-39-049-875-4179; E-mail: livio.trentin@unipd.it.

Antonella Contri and Anna Maria Brunati contributed equally to this work.

J. Clin. Oncol. 21:1874-1881.

8. Lin, T.S., Lucas, M.S., and Byrd, J.C. 2003. Rituximab in B-cell chronic lymphocytic leukemia. Semin. Oncol. 30:483-492.

9. Alfarano, A., et al. 1999. Alternative splicing of CD79a (Ig alpha) and CD79b (Ig beta) transcripts in human B-CLL cells. Curr. Top. Microbiol. Immunol. 246:241-246; discussion 247-248.

10. Indraccolo, S., et al. 2002. Alternatively spliced forms of Igalpha and Igbeta prevent B cell receptor expression on the cell surface. Eur. J. Immunol. 32:1530-1540.

11. Payelle-Brogard, B., Magnac, C., Alcover, A., Roux, P., and Dighiero, G. 2002. Defective assembly of the B-cell receptor chains accounts for its low expression in B-chronic lymphocytic leukaemia. Br. J. Haematol. 118:976-985.

12. Thompson, A.A., et al. 1997. Aberrations of the $\mathrm{B}$-cell receptor B29 (CD79b) gene in chronic lymphocytic leukemia. Blood. 90:1387-1394.

13. Gordon, M.S., et al. 2000. Aberrant B cell receptor signaling from B29 (Igbeta, CD79b) gene mutations of chronic lymphocytic leukemia B cells.
Proc. Natl. Acad. Sci. U. S. A. 97:5504-5509.

14. Zomas, A.P., et al. 1996. Expression of the immunoglobulin-associated protein B29 in B cell disorders with the monoclonal antibody SN8 (CD79b). Leukemia. 10:1966-1970.

15. Stevenson, F.K., and Caligaris-Cappio, F. 2004 Chronic lymphocytic leukemia:revelations from the B-cell receptor. Blood. 103:4389-4395.

16. Kawauchi, K., Ogasawara, T., and Yasuyama, M. 2002. Activation of extracellular signal-regulated kinase through B-cell antigen receptor in B-cell chronic lymphocytic leukemia. Int. J. Hematol. 75:508-513.

17. Healy, J.I., and Goodnow, C.C. 1998. Positive versus negative signaling by lymphocyte antigen receptors. Annu. Rev. Immunol. 16:645-670.

18. Kurosaki, T. 1998. Molecular dissection of B cell antigen receptor signaling [review]. Int. J. Mol. Med. 1:515-527.

19. Niiro, H., and Clark, E.A. 2002. Regulation of B-cell fate by antigen-receptor signals. Nat. Rev. Immunol. 2:945-956.

20. Cambier,J.C. 1995. Antigen and Fc receptor signaling. 
The awesome power of the immunoreceptor tyrosine-based activation motif (ITAM). J. Immunol. 155:3281-3285.

21. Bain, J., McLauchlan, H., Elliott, M., and Cohen, P. 2003. The specificities of protein kinase inhibitors: an update. Biochem. J. 371:199-204.

22. Oliver, J.M., Burg, D.L., Wilson, B.S., McLaughlin, J.L., and Geahlen, R.L. 1994. Inhibition of mast cell Fc epsilon R1-mediated signaling and effector function by the Syk-selective inhibitor, piceatannol. J. Biol. Chem. 269:29697-29703.

23. Mahajan, S., et al. 1999. Rational design and synthesis of a novel anti-leukemic agent targeting Bruton's tyrosine kinase (BTK), LFM-A13 [-cyano-hydroxy--methyl- $N$-(2,5-dibromophenyl)propena mide]. J. Biol. Chem. 274:9587-9599.

24. Meydan, N., et al. 1996. Inhibition of acute lymphoblastic leukaemia by a Jak-2 inhibitor. Nature. 379:645-648

25. Tse, K.F., et al. 2002. Inhibition of the transforming activity of FLT3 internal tandem duplication mutants from AML patients by a tyrosine kinase inhibitor. Leukemia. 16:2027-2036.

26. Burgel, P.R., et al. 2001. Human eosinophils induce mucin production in airway epithelial cells via epidermal growth factor receptor activation. J. Immunol. 167:5948-5954.

27. Takagi, S., et al. 1991. Intracellular localization of tyrosine kinase substrates beneath crosslinked surface immunoglobulins in B cells. J. Exp. Med. 174:381-388

28. Kharbanda, S., Yuan, Z.M., Rubin, E., Weichselbaum, R., and Kufe, D. 1994. Activation of Src-like p56/p53lyn tyrosine kinase by ionizing radiation. J. Biol. Chem. 269:20739-20743.

29. Donella-Deana, A., et al. 1998. Spontaneous autophosphorylation of Lyn tyrosine kinase at both its activation segment and C-terminal tail confers altered substrate specificity. Biochemistry. 37:1438-1446.

30. Pleiman, C.M., D’Ambrosio, D., and Cambier, J.C. 1994. The B-cell antigen receptor complex: structure and signal transduction. Immunol. Today. 15:393-399.

31. Reth, M., and Wienands, J. 1997. Initiation and pro- cessing of signals from the B cell antigen receptor. Annu. Rev. Immunol. 15:453-479.

32. Gupta, N., and DeFranco, A.L. 2003. Visualizing lipid raft dynamics and early signaling events during antigen receptor-mediated B-lymphocyte activation. Mol. Biol. Cell. 14:432-444.

33. Pierce, S.K. 2002. Lipid rafts and B-cell activation. Nat. Rev. Immunol. 2:96-105.

34. Kofler, R. 2000. The molecular basis of glucocorticoid-induced apoptosis of lymphoblastic leukemia cells. Histochem. Cell Biol. 114:1-7.

35. Koski, T., Aine, R., Vilpo, L., and Vilpo, J. 2000. Cyclosporin A-induced cell kill in vitro in various clinical-hematological types of B-cell chronic lymphocytic leukemia. Leuk. Res. 24:805-812.

36. Gupta, S., Hastak, K., Afaq, F., Ahmad, N., and Mukhtar, H. 2004. Essential role of caspases in epigallocatechin-3-gallate-mediated inhibition of nuclear factor kappaB and induction of apoptosis. Oncogene. 23:2507-2522.

37. Deana, R., et al. 2003. Green tea epigallocatechin3 -gallate inhibits platelet signalling pathways triggered by both proteolytic and non-proteolytic agonists. Thromb. Haemost. 89:866-874.

38. Masdehors, P., et al. 2000. Deregulation of the ubiquitin system and 553 proteolysis modify the apoptotic response in B-CLL lymphocytes. Blood. 96:269-274.

39. Bhattacharyya, S.P. 2001. Ubiquitination of Lynkinase in rat basophilic leukemia RBL-2H3 cells. Immunol. Lett. 75:131-136.

40. Luciano, F., Ricci, J.E., and Auberger, P. 2001. Cleavage of Fyn and Lyn in their N-terminal unique regions during induction of apoptosis: a new mechanism for Src kinase regulation. Oncogene. 20:4935-4941.

41. Lanham, S., et al. 2003. Differential signaling via surface IgM is associated with $\mathrm{VH}$ gene mutational status and CD38 expression in chronic lymphocytic leukemia. Blood. 101:1087-1093.

42. Xu, W., Harrison, S.C., and Eck, M.J. 1997. Threedimensional structure of the tyrosine kinase c-Src. Nature. 385:595-602.

43. Moarefi, I., et al. 1997. Activation of the Src-family tyrosine kinase Hck by SH3 domain displacement.
Nature. 385:650-653.

44. Thomas, M.L., and Brown, E.J. 1999. Positive and negative regulation of Src-family membrane kinases by CD45. Immunol. Today. 20:406-411.

45. Wei, S., et al. 1996. Critical role of Lyn kinase in inhibition of neutrophil apoptosis by granulocytemacrophage colony-stimulating factor. J. Immunol. 157:5155-5162.

46. Yousefi, S., Hoessli, D.C., Blaser, K., Mills, G.B., and Simon, H.U. 1996. Requirement of Lyn and Syk tyrosine kinases for the prevention of apoptosis by cytokines in human eosinophils. J. Exp. Med. 183:1407-1414.

47. Pazdrak, K., Olszewska-Pazdrak, B., Stafford, S., Garofalo, R.P., and Alam, R. 1998. Lyn, Jak2, and Raf- 1 kinases are critical for the antiapoptotic effect of interleukin 5, whereas only Raf-1 kinase is essential for eosinophil activation and degranulation. J. Exp. Med. 188:421-429.

48. Bates, R.C., Edwards, N.S., Burns, G.F., and Fisher, D.E. 2001. A CD44 survival pathway triggers chemoresistance via lyn kinase and phosphoinositide 3-kinase/Akt in colon carcinoma cells. Cancer Res. 61:5275-5283.

49. Saijo, K., et al. 2003. Essential role of Src-family protein tyrosine kinases in NF-kappaB activation during B cell development. Nat. Immunol. 4:274-279.

50. Trentin, L., et al. 1992. Expression and functional role of the p75 interleukin 2 receptor chain on leukemic hairy cells. Cancer Res. 52:5223-5228.

51. Trentin, L., et al. 2000. B7 costimulatory molecules from malignant cells in patients with B-cell chronic lymphoproliferative disorders trigger t-cell proliferation. Cancer. 89:1259-1268.

52. Cerutti, A., et al. 1996. The CD5/CD72 receptor system is coexpressed with several functionally relevant counterstructures on human B cells and delivers a critical signaling activity. J. Immunol. 157:1854-1862.

53. Brown, D.A., and London, E. 1998. Functions of lipid rafts in biological membranes. Annu. Rev. Cell Dev. Biol. 14:111-136.

54. Rai, K.R., et al. 1975. Clinical staging of chronic lymphocytic leukemia. Blood. 46:219-234. 